\title{
Perbandingan Pemberian Deksametason 10 mg dengan 15 mg Intravena sebagai Adjuvan Analgetik terhadap Skala Nyeri Pascabedah pada Pasien yang Dilakukan Radikal Mastektomi Termodifikasi
}

\author{
Muchammad Erias Erlangga, Ruli Herman Sitanggang, Tatang Bisri \\ Departemen Anestesiologi dan Terapi intensif \\ Fakultas Kedokteran Universitas Padjadjaran/Rumah Sakit Dr. Hasan Sadikin Bandung
}

\begin{abstract}
Abstrak
Deksametason merupakan kortikosteroid yang memiliki efek anti-inflamasi paling kuat. Penelitian ini bertujuan membandingkan deksametason $10 \mathrm{mg}$ dengan deksametason $15 \mathrm{mg}$ intravena prabedah terhadap nyeri pascabedah dan kebutuhan analgetik opioid. Penelitian ini merupakan uji acak terkontrol buta ganda pada 60 wanita dengan status fisik American Society of Anesthesiologist (ASA) I-II yang menjalani pembedahan radikal mastektomi termodifikasi dalam anestesi umum di Rumah Sakit Dr. Hasan Sadikin Bandung periode Desember 2013-April 2014. Pasien dibagi menjadi dua kelompok, yaitu 30 orang menerima deksametason $10 \mathrm{mg}$ dan 30 orang menerima deksametason $15 \mathrm{mg}$ yang diberikan 30 menit prabedah. Penilaian skala nyeri menggunakan nilai numeric rating scale (NRS) pada saat istirahat dan mobilisasi, pada jam ke-1, 2, 4, 12 , dan 24 pascabedah. Pemberian analgetik tambahan opioid dilakukan bila nilai NRS $>3$. Analisis statistika data hasil penelitian menggunakan uji-t, chi-kuadrat, dan Mann-Whitney. Hasil penelitian menunjukan nilai NRS saat istirahat pada kelompok deksametason $10 \mathrm{mg}$ dengan deksametason $15 \mathrm{mg}$ tidak berbeda bermakna $(p>0,05)$, sementara nilai NRS saat mobilisasi pada kelompok deksametason $10 \mathrm{mg}$ lebih tinggi dibanding dengan kelompok deksametason $15 \mathrm{mg}(\mathrm{p}<0,05)$. Pemberian analgetik tambahan pascabedah tidak terdapat perbedaan secara bermakna antara kedua kelompok $(p>0,05)$. Simpulan penelitian ini adalah pemberian deksametason $15 \mathrm{mg}$ dapat diberikan karena mempunyai efek analgesia yang lebih baik.
\end{abstract}

Kata kunci: Deksametason, numeric rating scale, nyeri pascabedah

\section{Comparison between $10 \mathrm{mg}$ and $15 \mathrm{mg}$ of Intravenous Dexamethasone as Analgesia Adjunct on Post Operative Pain in Patients Undergo Modified Radical Mastectomy}

\begin{abstract}
Dexamethasone is a glucocorticoid with the strongest anti-inflammatory property. The aim of this study was to compare the effect of $10 \mathrm{mg}$ and $15 \mathrm{mg}$ of intravenous dexamethasone on post operative pain and opioid analgetic need. This was a randomized double-blind study involving 60 females with physical status ASA I-II whom underwent modified radical mastectomy under general anesthesia at Dr. Hasan Sadikin General Hospital during December 2013-April 2014. Patients were divided into 2 groups where 30 patients received $10 \mathrm{mg}$ dexamethasone and 30 patients received $15 \mathrm{mg}$ dexamethasone 30 minutes prior to surgery. Pain assessment was performed using numeric rating scare (NRS) at rest and during activity, documented on the $1^{\text {st }}, 2^{\text {nd }}, 4^{\text {th }}, 12^{\text {th }}$ and $24^{\text {th }}$ hour post operative. Additional analgesia was given if NRS $>3$. Data were analyzed statistically using Student's t test, chi-square and Mann Whitney U test. Result showed that the difference between NRS at rest for $10 \mathrm{mg}$ and $15 \mathrm{mg}$ dexamethasone ( $p>0.05$ ) was not significant, while the difference in NRS during activity at all time measurements were statistically significant $(p<0.05)$. There was no statistical significant difference in additional opioid administered between the two groups ( $p>0.05$ ). This study concludes that $15 \mathrm{mg}$ dexamethasone has a better analgesia effect to reduce analgesic dose.
\end{abstract}

Key words: Dexamethasone, numeric rating scale, post operative pain

Korespondensi: Muchammad Erias Erlangga, dr., SpAn, Departemen Anestesiologi dan Terapi Intensif Fakultas Kedokteran Universitas Padjadjaran/Rumah Sakit Dr. Hasan Sadikin Bandung, Jl. Pasteur No. 38 Bandung 40161, Tlp 022-2038285, Faks 022-2038306, Mobile 0818202974, Email erias157@gmail.com 


\section{Pendahuluan}

Nyeri adalah reaksi fisiologis terhadap cedera jaringan, distensi viseral, atau sebagai respons terhadap penyakit yang bersifat subjektif, dan dirasakan pasien sebagai pengalaman sensoris serta emosional yang tidak menyenangkan. Nyeri yang dirasakan oleh pasien merupakan hasil akhir mekanisme interaksi yang sangat kompleks pada sistem saraf. ${ }^{1-3}$

Penatalaksanaan nyeri pascabedah yang tidak adekuat dapat memperlambat proses pemulihan, memperpanjang masa perawatan, meningkatkan biaya, dan menurunkan tingkat kepuasaan pasien atas tindakan pembedahan. ${ }^{4}$

Tujuan dari penanganan nyeri pascabedah ialah pemulihan fungsi organ secara cepat dan juga menghindari komplikasinya. Penanganan nyeri yang baik akan mengurangi morbiditas dan komplikasi pascabedah, meningkatkan kenyamanan dan kepuasan pasien, mobilisasi lebih dini, mempercepat penyembuhan pasien, serta mengurangi biaya perawatan di rumah sakit. $^{5}$

Tumor ganas payudara merupakan jenis tumor yang paling sering menyerang wanita dengan persentase (\%) tingkat kelangsungan hidup selama lima tahun di atas $80 \%$. Radikal mastektomi termodifikasi merupakan jenis pembedahan dengan skala nyeri pascabedah yang cukup tinggi, yaitu 4-8 dari skala nyeri maksimal 10 sehingga jenis pembedahan ini membutuhkan penanganan nyeri pascabedah yang baik. ${ }^{6}$

Tingginya tingkat nyeri yang timbul pada saat periode pascabedah dapat menyebabkan nyeri yang kronik (chronic post surgical pain). Gejala nyeri yang menetap setelah dilakukan tindakan pembedahan akan berdampak buruk terhadap kualitas hidup seseorang. Nyeri yang terjadi akibat pembedahan tumor ganas payudara merupakan nyeri inflamasi, hal ini disebabkan oleh insisi dan kerusakan jaringan yang dapat menimbulkan proses inflamasi sehingga terjadi pelepasan mediator-mediator inflamasi. Mediator-mediator ini mengaktifasi nosiseptor untuk terjadinya sensitisasi perifer. $2,6,7$

Pengetahuan mengenai mekanisme serta substansi dari proses inflamasi menghasilkan strategi untuk memberikan analgesia yang adekuat. Hal ini berdasar pada bagaimana cara mengurangi, menghambat, dan juga menekan proses inflamasi. $^{2}$

Kortikostreoid merupakan anti-inflamasi yang bekerja dengan mekanisme menghambat enzim fosfolipase A2 sehingga akan mencegah pelepasan asam arakidonatyang memproduksi enzim cyclooxygenase (COX). Enzim COX inilah yang bertanggung jawab atas pembentukan prostaglandin yang merupakan mediator inflamasi dan nyeri. ${ }^{2}$

Deksametason merupakan kortikosteroid dari golongan glukokortikoid yang mempunyai efek anti-inflamasi yang adekuat. Pemberian deksametason akan menekan pembentukan bradikinin dan juga pelepasan neuropeptida dari ujung-ujung saraf, hal tersebut dapat menimbulkan rangsangan nyeri pada jaringan yang mengalami proses inflamasi. Penekanan produksi prostaglandin oleh deksametason akan menghasilkan efek analgesia melalui penghambatan sintesis enzim cyclooksigenase di jaringan perifer tubuh. Deksametason juga menekan mediator inflamasi seperti tumor necrosis factor- $\alpha$ (TNF- $\alpha$ ), interleukin $1-\beta$ (IL-1 $\beta)$, dan interleukin-6 (IL-6). ${ }^{8}$

Pada satu dekade terakhir efek analgesik dari betametason, deksametason, dan juga metilprednisolon banyak diteliti pada berbagai macam jenis pembedahan. ${ }^{8-11}$

Dosis deksametason untuk pencegahan mual dan muntah pascabedah telah ditetapkan, akan tetapi dosis optimal sebagai adjuvan dari deksametason belum dapat ditentukan. ${ }^{9}$ Dosis deksametason yang dipergunakan untuk penelitian berkisar 5-40 mg. ${ }^{12,13}$

Penelitian deksametason $10 \mathrm{mg}$ intravena dibanding dengan plasebo pada pembedahan tonsilektomi menghasilkan penurunan nyeri yang bermakna. ${ }^{14}$ Pemberian deksametason $15 \mathrm{mg}$ intravena pada penelitian lain dapat menurunkan skala nyeri bila dibanding dengan deksametason 8 mg pada pembedahan kepala dan leher. ${ }^{15}$

Pada penelitian ini akan diungkapkan dosis optimal adjuvan deksametason dengan cara membandingkan pemberian deksametason 
$10 \mathrm{mg}$ dengan $15 \mathrm{mg}$ intravena saat prabedah terhadap skala nyeri pascabedah dan juga kebutuhan analgetik opioid pada pembedahan radikal mastektomi termodifikasi.

\section{Subjek dan Metode}

Metode penelitian yang dipergunakan bersifat eksperimental. Penelitian dilakukan dengan melakukan uji acak terkontrol buta ganda (double blind randomized controlled trial).

Sebanyak 60 pasien yang dirawat di Rumah Sakit Dr. Hasan Sadikin (RSHS) Bandung yang menjalani pembedahan radikal mastektomi termodifikasi elektif dengan status fisik menurut American Society of Anesthesiologist (ASA) kelas I-II pada periode Desember 2013April 2014 dimasukkan sebagai kriteria inklusi. Riwayat alergi terhadap obat golongan opioid, ketorolak, mempunyai riwayat penyakit ulkus peptikum, gangguan hati dan ginjal, diabetes melitus, sedang mendapatkan terapi analgetik (opioid, tramadol, parasetamol, obat antiinflamasi nonsteroid), dan juga skala hamilton anxiety rating scale $>25$ (kecemasan berat) merupakan kriteria eksklusi pada penelitian ini. Penarikan sampel dilakukan secara random sampling, yaitu berdasarkan tabel bilangan acak yang terlebih dahulu telah dibuat.

Setelah mendapatkan persetujuan Komite Etik Penelitian Kesehatan Fakultas Kedokteran Universitas Padjadjaran/Rumah Sakit Dr. Hasan Sadikin Bandung, dilakukan kunjungan prabedah 1 (satu) hari sebelum operasi dan juga dilakukan penandatanganan formulir persetujuan (informed consent) kepada pasien mengenai operasi dan penelitian yang akan dilaksanakan, dan dijelaskan tentang tata cara penilaian numeric rating scale (NRS).

Semua subjek dipuasakan selama enam jam sebelum operasi dari makanan padat dan dua jam sebelum operasi dari air bening. Randomisasi sampel dilakukan menggunakan tabel bilangan random, kemudian sampel tersebut dibagi menjadi 2, yaitu kelompok D10 (deksametason $10 \mathrm{mg}, \mathrm{n}=30$ ) dan kelompok D15 (deksametason $15 \mathrm{mg}, \mathrm{n}=30$ ). Semua kelompok mendapatkan premedikasi dengan lorazepam (ativan) 0,5 mg pada malam hari.
Tiga puluh menit sebelum masuk ruang operasi, saat di ruang persiapan pasien diukur tingkat kecemasan memakai skala Hamilton, kemudian pasien kelompok D10 diberikan deksametason $10 \mathrm{mg}$ intravena dan kelompok D15 diberikan deksametason 15 mg intravena. Di dalam ruang operasi pasien dibaringkan terlentang, dilakukan pemasangan alat pantau, serta dicatat pula data mengenai kesadaran, tekanan darah, laju nadi, laju napas, dan juga saturasi oksigen. Selanjutnya, dipasang kateter intravena dengan jarum 18G dan diberikan cairan infus Ringer laktat $10 \mathrm{~mL} / \mathrm{kgBB}$.

Proses induksi anestesi dilakukan dengan memberikan fentanil $1 \mathrm{mcg} / \mathrm{kgBB}$, propofol 2 $\mathrm{mg} / \mathrm{kgBB}$, atrakurium $0,5 \mathrm{mg} / \mathrm{kgBB}$, setelah 3 menit kemudian dilakukan laringoskopi serta intubasi. Pemeliharaan kedalaman anestesi dilakukan memakai isofluran dan $\mathrm{N}_{2} \mathrm{O}: \mathrm{O}_{2} 50 \%$. Sebelum dilakukan sayatan diberikan kembali fentanil sebanyak $1 \mathrm{mcg} / \mathrm{kgBB}$. Saat tiga puluh menit menjelang akhir operasi diberikan bolus analgetik ketorolak 0,5 mg/kgBB. Pada akhir operasi diberikan antagonis pelumpuh otot memakai neostigmin $0,04 \mathrm{mg} / \mathrm{kgBB}$ dan sulfas atropin $0,06 \mathrm{mg} / \mathrm{kgBB}$. Pencegahan terhadap mual dan muntah diberikan ondansetron $4 \mathrm{mg}$ intravena, selanjutnya analgetik pascabedah menggunakan ketorolak 3x30 mg selama tiga hari.

Pasien diekstubasi kemudian dipindahkan ke ruang pemulihan serta dilakukan observasi selama 24 jam. Penilaian nyeri pascabedah dilakukan dengan memakai numeric rating scale (NRS) pada jam ke-1, 2, 4, 12, dan 24 pascabedah. Pencatatan skor nyeri, laju nadi, tekanan darah, saturasi perifer $\mathrm{O}_{2}$, laju napas, efek samping, penggunaan petidin tambahan, dan juga penggunaan total petidin dilakukan selama 24 jam. Bila nilai NRS lebih dari 3 diberikan analgetik penyelamatan memakai petidin $25 \mathrm{mg}$. Bila nilai NRS masih lebih dari 3, maka 15 menit kemudian dapat diberikan analgetik pertolongan ulangan. Apabila pasien merasakan kesakitan di luar jam observasi penelitian ini maka dilakukan penilaian skor nyeri dengan NRS oleh residen jaga anestesi yang bertugas di ruang resusitasi. Pemberian petidin dihentikan apabila laju napas $<12 x$ / 
Tabel 1 Karakteristik Umum Subjek Penelitian Kedua Kelompok Perlakuan

\begin{tabular}{lccc}
\hline \multirow{2}{*}{ Karakteristik Umum } & \multicolumn{2}{c}{ Kelompok } & \multirow{2}{*}{ Nilai p } \\
\cline { 2 - 3 } Usia (tahun) & D10 mg (n=30) & D15 mg (n=30) & \\
Rata-rata (SD) & $49,5(9,4)$ & $48,8(8,3)$ & $0,761^{*}$ \\
Rentang & $31-65$ & $34-65$ & \\
Pendidikan & & & \\
SD & 7 & 8 & $0,720^{* *}$ \\
SMP & 10 & 6 & \\
SMA & 7 & 9 & \\
Perguruan tinggi & 6 & 7 & $0,460^{* *}$ \\
Berat badan (kg) & & $51,5(4,1)$ & \\
Rata-rata (SD) & $50,7(2,5)$ & $45-60$ & $0,185^{*}$ \\
Rentang & $45-55$ & & \\
Body mass index (kg/m $\left.{ }^{2}\right)$ & & $21(1,5)$ & \\
Rata-rata (SD) & $20,5(1,2)$ & $18,7-24,9$ & \\
Rentang & $18,7-24$ & & \\
Lama operasi (menit) & & $180(17,2)$ & $0,944^{* *}$ \\
Rata-rata (SD) & $181,5(22,4)$ & $150-210$ & \\
Rentang & $150-265$ & $1,6(0,03)$ & \\
Tinggi badan (cm) & & $1,5-1,63$ & \\
Rata-rata (SD) & $1,6(0,03)$ & & \\
Rentang & $1,5-1,63$ & & \\
\hline
\end{tabular}

Keterangan: *) uji-t ${ }^{* *}$ ) Uji Mann-Whitney

menit, saturasi oksigen $<95 \%$, dan atau timbul efek samping yang serius akibat pemakaian petidin.

Analisis statistik terhadap hasil penelitian mempergunakan uji-t, chi-kuadrat, dan MannWhitney dengan tingkat kepercayaan 95\% dan dianggap bermakna bila $\mathrm{p}<0,05$. Data disajikan dalam rata-rata (mean) dan dianalisis dengan menggunakan program statistical product and service solution (SPSS) 20 for windows.

\section{Hasil}

Karakterisitik umum subjek penelitian kedua kelompok berdasarkan usia, pendidikan, berat badan, body mass index (BMI), lama operasi,

Tabel 2 Perbandingan Tingkat Ansietas antara Kedua Kelompok Perlakuan

\begin{tabular}{|c|c|c|c|}
\hline \multirow{2}{*}{ Tingkat Ansietas } & \multicolumn{2}{|c|}{ Kelompok } & \multirow{2}{*}{ Nilai p } \\
\hline & D10 mg (n=30) & D15 mg $(n=30)$ & \\
\hline Ringan (skala HARS 7-14) & 21 & 21 & \multirow{2}{*}{1,000} \\
\hline Sedang (skala HARS 15-27) & 9 & 9 & \\
\hline
\end{tabular}

Keterangan: *nilai p dihitung dengan uji chi-square continue correction 
Tabel 3 Perbandingan Nilai NRS Saat Istirahat antara Kedua Kelompok

\begin{tabular}{cccccc}
\hline \multirow{3}{*}{ Waktu Pengukuran } & \multicolumn{4}{c}{ Kelompok } & \multirow{2}{*}{ Nilai p } \\
\cline { 2 - 5 } & \multicolumn{2}{c}{ D10 mg (n=30) } & \multicolumn{2}{c}{ D15 mg (n=30) } & \\
\cline { 2 - 5 } & Median & Rentang & Median & Rentang & \\
\hline $\mathrm{T}_{1}$ & 2 & $1-2$ & 2 & $1-2$ & 0,409 \\
$\mathrm{~T}_{2}$ & 2 & $1-3$ & 2 & $1-2$ & 0,977 \\
$\mathrm{~T}_{4}$ & 2 & $1-4$ & 2 & $1-3$ & 0,748 \\
$\mathrm{~T}_{12}$ & 2 & $1-3$ & 2 & $1-3$ & 0,113 \\
$\mathrm{~T}_{24}$ & 2 & $1-2$ & 2 & $1-3$ & 0,260 \\
\hline
\end{tabular}

Keterangan: T1=jam ke-1, $\mathrm{T}_{2}=$ jam ke-2, dan seterusnya. Nilai $\mathrm{p}$ dihitung berdasarkan Uji Mann-Whitney. Nilai $\mathrm{p}$ bermakna jika $\mathrm{p}<0,05$

dan juga tinggi badan tidak berbeda bermakna secara statistika ( $p>0,05$; Tabel 1).

Hasil pengukuran dari tingkat ansietas atau kecemasan terhadap kelompok deksametason $10 \mathrm{mg}$ dan juga deksametason $15 \mathrm{mg}$ secara statistika tidak menunjukkan perbedaan yang bermakna ( $p=1,000$; Tabel 2).

Rentang nilai NRS pada saat istirahat secara keseluruhan didapatkan 1-4 pada kelompok deksametason $10 \mathrm{mg}$ dan rentang 1-3 pada kelompok deksametason $15 \mathrm{mg}$. Berdasarkan hasil uji statistika, diketahui bahwa nilai NRS kedua kelompok pada waktu T1, T2, T4, T12, dan T24 tidak berbeda bermakna $(p<0,05$; Tabel 3).

Penilaian NRS saat mobilisasi dilakukan dengan menggerakkan lengan bagian atas pada sisi yang dilakukan tindakan pembedahan.
Rentang nilai NRS pada saat mobilisasi secara keseluruhan didapatkan 1-5 pada kelompok deksametason $10 \mathrm{mg}$ dan rentang 1-5 pada kelompok deksametason $15 \mathrm{mg}$. Berdasarkan hasil uji statistika, diketahui bahwa nilai NRS kedua kelompok pada waktu T1, T2, T4, T12, serta T24 memperlihatkan perbedaan yang bermakna ( $\mathrm{p}<0,05$; Tabel 4$)$.

Pada kelompok deksametason $10 \mathrm{mg}$ hanya terdapat 6 dari 30 subjek yang diberikan tambahan analgetik, sedangkan kelompok deksametason $15 \mathrm{mg}$ terdapat empat dari 30 subjek yang mendapatkan tambahan analgetik dengan perbedaan tidak bermakna ( $\mathrm{p}>0,05$; Tabel 5).

Pada kelompok deksametason $10 \mathrm{mg}$ tidak terdapat subjek yang mengalami efek samping gangguan penyembuhan luka, namun

Tabel 4 Perbandingan Nilai NRS Saat Mobilisasi antara Kedua Kelompok

\begin{tabular}{|c|c|c|c|c|c|}
\hline \multirow{3}{*}{$\begin{array}{c}\text { Waktu } \\
\text { Pengukuran }\end{array}$} & \multicolumn{4}{|c|}{ Kelompok } & \multirow{3}{*}{ Nilai $_{\text {I }}$} \\
\hline & \multicolumn{2}{|c|}{$D 10(n=30)$} & \multicolumn{2}{|c|}{ D15 $(n=30)$} & \\
\hline & Median & Rentang & Median & Rentang & \\
\hline $\mathrm{T}_{1}$ & 2 & $1-3$ & 1,5 & $1-2$ & $0,000^{*}$ \\
\hline $\mathrm{T}_{2}$ & 2 & $1-4$ & 2 & $1-2$ & $0,000^{*}$ \\
\hline $\mathrm{T}_{4}$ & 3 & $1-5$ & 2 & $1-4$ & $0,000^{*}$ \\
\hline $\mathrm{T}_{12}$ & 3 & $1-5$ & 2 & $1-5$ & $0,006^{*}$ \\
\hline $\mathrm{T}_{24}$ & 2,5 & $1-3$ & 2 & $1-3$ & $0,005^{*}$ \\
\hline
\end{tabular}

Keterangan: $\mathrm{T} 1=1$ jam, T2=2 jam, dan seterusnya. Nilai p dihitung berdasarkan Uji Mann-Whitney. Nilai p bermakna jika $(\mathrm{p}<0,05)$ 
Tabel 5 Perbandingan Pemakaian Analgetik Tambahan antara Kedua Kelompok

\begin{tabular}{lccc}
\hline \multirow{2}{*}{ Variabel } & \multicolumn{2}{c}{ Kelompok } & \multirow{2}{*}{ Nilai p } \\
\cline { 2 - 3 } & $\mathbf{D ~ 1 0 ~} \mathbf{~ m g ~ ( n = 3 0 )}$ & D 15 $\mathbf{~ m g ~ ( n = 3 0 )}$ & \\
\hline Tanpa tambahan analgetik & 24 & 26 & \multirow{2}{*}{0,492} \\
Dengan tambahan analgetik & 6 & 4 & \\
\hline
\end{tabular}

Keterangan: nilai $p$ dihitung berdasarkan Uji Mann-Whitney. Nilai p bermakna jika $(p<0,05)$

terjadi peningkatan kadar gula darah pada satu orang dan juga gastritis pada dua orang, sedangkan pada kelompok deksametason 15 mg tidak didapatkan efek samping gangguan penyembuhan luka, terjadi peningkatan kadar gula darah pada 2 orang, dan gastritis pada 3 orang.

\section{Pembahasan}

Tujuan utama penanganan nyeri pascabedah adalah pemulihan fungsi organ secara cepat serta menghindari komplikasinya. Penanganan nyeri yang baik akan mengurangi morbiditas dan komplikasi pascabedah, meningkatkan kenyamanan dan kepuasan pasien, mobilisasi lebih dini, mempercepat penyembuhan, serta mengurangi biaya perawatan rumah sakit. ${ }^{5}$

Nyeri yang terjadi pascabedah merupakan nyeri nosiseptif yang terjadi sebagai akibat proses inflamasi. ${ }^{4,16}$ Deksametason merupakan kortikosteroid dari golongan glukokortikoid yang mempunyai efek anti-inflamasi yang paling kuat. Peranan deksametason di dalam menghambat sintesis enzim siklooksigenasi 1 dan 2 akan menekan produksi prostaglandin yang berfungsi sebagai mediator inflamasi dan nyeri sehingga terbentuklah efek analgesia. ${ }^{8,17}$
Efek deksametason tersebut dapat digunakan sebagai obat tambahan analgetik pascabedah.

Pada data karakteristik umum (Tabel 1) ternyata tidak menunjukkan perbedaan yang bermakna dalam hal usia, pendidikan, berat badan, BMI, lama operasi, dan tinggi badan. Hal ini menunjukkan bahwa sampel yang diambil untuk penelitian ini relatif homogen secara statistika $(p>0,05)$ sehingga kedua kelompok penelitian ini layak untuk diperbandingkan.

Salah satu faktor yang dapat menyebabkan tingkat keparahan pada nyeri akut pascabedah adalah tekanan terhadap emosi seseorang, kecemasan, serta depresi. Seseorang dengan tingkat kecemasan yang tinggi diperkirakan lebih reaktif secara psikologi dan juga sangat hipersensitif terhadap pemberian rangsangan atau stimuli. ${ }^{6,7}$ Pada penelitian ini persepsi subjek terhadap nyeri harus homogen agar kedua kelompok ini dapat diperbandingkan, oleh sebab itu dilakukanlah penilaian tingkat kecemasan mempergunakan Hamilton anxiety rating scale (HARS), dan didapatkan bahwa tingkat kecemasan prabedah antara kedua kelompok ini secara statistika tidak berbeda bermakna $(\mathrm{p}>0,05)$.

Pengukuran derajat nyeri mempergunakan numeric rating scale (NRS) dilakukan pada

Tabel 6 Perbandingan Efek Samping pada Kedua Kelompok Perlakuan

\begin{tabular}{lcc}
\hline \multicolumn{1}{c}{ Efek samping } & \multicolumn{2}{c}{ Kelompok } \\
\cline { 2 - 3 } & D10 $\mathbf{~ m g ~ ( n = 3 0 ) ~}$ & D15 mg (n=30) \\
\hline Gangguan penyembuhan luka & 0 & 0 \\
Peningkatan gula darah & 1 & 2 \\
Gastritis & 2 & 3 \\
\hline
\end{tabular}

Keterangan: nilai $p$ dihitung berdasarkan uji chi-kuadrat. Nilai p bermakna jika $(p<0,05)$. Tanda *menunjukkan tidak bermakna atau tidak signifikan. Nilai persentase merupakan pembagian terhadap 30 subjek 
saat pasien beristirahat atau tidak bergerak maupun pada saat melakukan aktivitas seperti menggerakkan lengan bagian atas. Hasil dari penelitian ini menunjukkan bahwa kelompok deksametason $10 \mathrm{mg}$ mempunyai rentang nilai NRS 1-4 dan kelompok deksametason 15 mg mempunyai rentang nilai NRS $1-3$ pada saat istirahat, sementara pada saat beraktivitas kedua kelompok perlakuan memiliki rentang nilai NRS yang sama yaitu 1-5. Hasil uji statistika mempergunakan Uji Mann-Whitney didapatkan perbedaan yang bermakna pada pengukuran NRS pada saat beraktivitas antara kedua kelompok perlakuan.

Penilaian skala nyeri dengan menggunakan numeric rating scale (NRS) yang juga diikuti dengan penilaian jumlah kebutuhan analgetik pertolongan yang dilakukan untuk mengetahui kemampuan analgesia yang adekuat selama waktu tertentu. Pemberian adjuvan analgetik dapat menurunkan 20-50\% kebutuhan opioid (opioid sparring effect) pada saat pascabedah. Hasil penelitian ini memberikan gambaran bahwa pada kelompok deksametason $10 \mathrm{mg}$, analgetik petidin tambahan diberikan pada 6 dari 30 pasien, sedangkan pada kelompok deksametason $15 \mathrm{mg}$ diberikan pada 4 dari 30 pasien yang secara statistika perbedaan ini tidaklah bermakna $(\mathrm{p}>0,05)$.

Hasil tersebut tidak sejalan dengan hasil penelitian sebelumnya yang membandingkan deksametason $15 \mathrm{mg}$ dengan plasebo yang ternyata dapat menurunkan jumlah kebutuhan opioid pascabedah laparaskopi histerektomi. Penelitian tersebut juga menyatakan bahwa penurunan kebutuhan opioid saat 2 (dua) jam pascabedah terhadap pasien yang diberikan deksametason $10 \mathrm{mg}$ sama efektifnya dengan yang diberikan deksametason $15 \mathrm{mg}{ }^{12}$ Penulis berpendapat tingkat nyeri pada pasien yang telah dilakukan tindakan radikal mastektomi termodifikasi lebih tinggi dibanding dengan laparaskopi histerektomi sehingga kebutuhan analgetik petidin automatis akan bertambah dan penurunan kebutuhannya tidak terlihat bermakna. Pada penelitian ini tidak dilakukan kesetaraan antara deksametason dan obat lain.

Berdasarkan hasil statistika, nilai NRS saat mobilisasipada kelompokdeksametason $10 \mathrm{mg}$ lebih tinggi dibanding dengan nilai NRS pada kelompok deksametason $15 \mathrm{mg}$, perbedaan pada nilai NRS tersebut berhubungan dengan dosis obat yang diberikan. Pada penelitian sebelumnya dinyatakan juga bahwa pemberian deksametason dengan konsentrasi yang tinggi akan memberikan efek yang maksimal. ${ }^{18}$ Hasil penelitian ini memang membuktikan bahwa dosis yang lebih besar dapat menurunkan nilai NRS dengan perbedaan yang bermakna secara statistika.

Hasil lain penelitian ini adalah efek samping yang dapat ditimbulkan oleh deksametason seperti peningkatan risiko infeksi yang dapat mengganggu penyembuhan luka, peningkatan kadar gula darah, dan gastritis yang ditemukan hanya pada beberapa subjek kedua kelompok perlakuan. Pemberian deksametason dengan dosis tunggal tidak akan menyebabkan terjadi efek samping. ${ }^{19}$ Gejala seperti peningkatan risiko infeksi, peningkatan kadar gula darah, penyembuhan luka yang terlambat, gastritis, dan juga supresi adrenal akan timbul pada pemberian deksametason dosis ganda yang kronis. ${ }^{19,20}$ Pada penelitian terdahulu, Bisgaard dkk. ${ }^{9}$ memberikan deksametason $8 \mathrm{mg}$ dosis tunggal pada pembedahanan kolesistektomi per laparaskopi, hasil observasi dalam 30 hari pada penelitian tersebuttidak memperlihatkan efek samping. ${ }^{9}$

Penelitian yang memberikan dosis tunggal deksametason $20 \mathrm{mg}$ terhadap pembedahan tonsilektomi pada dewasa tidak menunjukkan efek samping, bahkan mereka menyatakan bahwa kortikosteroid dosis tunggal meskipun dalam dosis besar tidak terlihat efek yang membahayakan. ${ }^{18}$

\section{Simpulan}

Simpulan penelitian ini adalah pemberian deksametason $15 \mathrm{mg}$ intravena lebih baik dibanding dengan deksametason $10 \mathrm{mgsebagai}$ adjuvan analgetik dalam mengurangi nilai NRS pascabedah saat mobilisasi pada pembedahan radikal mastektomi termodifikasi. Namun, tidak lebih baik dalam mengurangi kebutuhan analgetik opioid pascabedah. 
Berdasarkan atas hasil penelitian ini dapat direkomendasikan pemberian deksametason $15 \mathrm{mg}$ intravena prabedah sebagai adjuvan analgetik dalam mengurangi NRS pascabedah radikal mastektomi termodifikasi. Pemberian dosis tunggal tersebut tidakakan menimbulkan efek samping yang berarti sehingga disarankan memberikan dosis tunggal deksametason 15 mg prabedah yang dapat menurunkan nilai NRS tanpa efek samping yang merugikan.

\section{Daftar Pustaka}

1. Lubenow TR, Ivankovich AD, Barkin RL. Management of acute post operative pain. Dalam: Barash PG, Cullen BF, Stoelting RK, penyunting. Clinical anesthesia. Edisi ke-5. Philadelphia: Lippincott William \& Wilkins; 2006. hlm. 1405-6.

2. Kirwan T. Post-operative pain. Dalam: Holdcroft A, Jaggar S, penyunting. Core topics in pain. New York: Cambridge University Press; 2005. hlm. 161-70.

3. Habib AS, Gan TJ. Role of analgesic adjuncts in post-operative pain management. Anesthesiol Clin N Am. 2005;23:85-107.

4. Salerno A. Efficacy and safety of steroid use for postoperative pain relief. Update and review of the medical literature. J Bone Joint Surg Am. 2006;88(6):1361-72.

5. Sarantopoulus C. A practical approach to postoperative pain management. Dalam: Abram S, penyunting. Pain medicine: the requisites in anesthesiology. Edisi ke-1. Philadelphia: Mosby Elsevier's; 2006. hlm. 98-113.

6. Bruce J, Thornton AJ, Scott NW. Chronic preoperative pain psychological robustness predict acute post operative pain outcomes after surgery for breast cancer. Br J Cancer. 2012;107:937-46.

7. Bruce J, Quinlan J. Chronic surgical pain. Br J Pain. 2011;5(3):23-7.

8. Romundstad L, Breivik $\mathrm{H}$, Roald $\mathrm{H}$, Skolleborg K, Haugen T, Narum J, dkk. Methylprednisolone reduces pain, emesis, and fatigue after breast augmentation surgery: a single dose, randomized parallel group study with methylprednisolone 125 $\mathrm{mg}$, parecoxib $40 \mathrm{mg}$, and placebo. Anesth Analg. 2006;102:418-25.

9. Bisgaard T, Klarskov B, Kehlet H, Rosenborg J. Preoperative dexamethasone improves surgical outcome after laparascopic cholecystectomy. A randomized doubleblind placebo-controlled trial. Ann Surg.
2003;238:651-60.

10. Kjetil H, Sem TK, Ellen S, Johan R. The prolonged postoperative analgesic effect when dexamethasone is added to a nonsteroidal antiinflammatory drug (rofecoxib) before breast surgery. Anesth Analg. 2007;105:481-6.

11. Kardash KJ, Sarrazin F, Tessler MJ, Velly AM. Single-dose dexamethasone reduces dynamic pain after total hip arthroplasty. Anesth Analg. 2008;106:1253-7.

12. Jokela RM, Ahonen JV, Tallgren MK, Marjakangas PC, Korttila KT. The effective analgesic dose of dexamethasone after laparoscopic hysterectomy. Anesth Analg. 2009;109:607-15.

13. Bergeron SG, Kardash KJ. Perioperative dexamethasone does not affect functional outcome in total hip arthroplasty. Clin Orthop Relat Res. 2009;467:1463-7.

14. McKean S, Kochilas X, Kelleher R, Dockery M. Use of intravenous steroids at inductionof anesthesia for adult tonsillectomy to reduce post-operative nausea and vomiting and pain. Clin Otolaryngol. 2006;31:36-40.

15. Nugroho YA. Perbandingan efek adjuvant analgesi dexamethasone $15 \mathrm{mg}$ dengan dexamethasone $8 \mathrm{mg}$ intravena pada pasca pembedahan kepala leher [Tesis]. Yogyakarta: Universitas Gadjah Mada; 2010.

16. Rao M. Acute postoperative pain. Indian J Anaesth. 2006;50(5):340-4.

17. Allen K. Dexamethasone: an all purpose agent?. Australian Anesthesia (Online Journal) 2007 (diunduh 21 Mei 2007). Tersedia dari: http://www.anzca.edu.au/ resources/college-publications/pdfs / books-and-publications/Australasian $\% 20$ Anaesthesia/australasian-anaesthesia2007/Allen.pdf.

18. Rujirojindakul P, Atchariyasathian $V$, Uakritdathikran T. Effect of dexamethasone on postoperative pain after adult tonsilectomy. Thai J Anesthesiol. 2008;34:1-8.

19. DjalaliA.Istherearolefor IV dexamethasone in perioperative pain management? J Pain Relief. 2012;1(5):1-2.

20. Shahraki A, Feizi A, Jabalameli M. The effect of intravenous dexamethasone on post-cesarean section pain and vital signs: a double-blind randomized clinical trial. J Res Pharm Pract. 2013;2:99-104. 
154 | Jurnal Anestesi Perioperatif 